\title{
Programa Escola Sem Partido: Repressão ou Liberdade Para o Ensino?
}

\author{
Programa Escuela sin Partido: Represión o Libertad para la Enseñanza? \\ Unparalleled School Program: Repression or Freedom for Teaching?
}

\author{
Paula Fernanda de Souza França ${ }^{1}$ \\ Alfredo Alejandro Gugliano ${ }^{2}$
}

\begin{abstract}
Resumo
O presente artigo estuda a oposição ao movimento e à implantação do programa "Escola sem Partido" no ensino brasileiro com dados coletados a partir de pesquisa bibliográfica e analisados pelo método de comparação. $\mathrm{O}$ trabalho foi dividido em três blocos: no primeiro, são apresentados os defensores do programa, expondo os principais pontos do histórico e dos objetivos do grupo "EscolasemPartido.org", dos contextos do Projeto de Lei n 190/2015-RS e do Projeto de Lei do Senado Federal no 193/2016, ponderando sobre os resultados dos anos de 2016 e 2017 da enquete do Senado Federal referente ao assunto. As ideias contrárias ao movimento e aos projetos de lei são apontadas no segundo bloco. No último bloco, utilizando de referências que versam sobre o assunto, são feitas reflexões críticas de modo a auxiliar o leitor a definir sua posição sobre a implantação do programa ao atual modelo de ensino brasileiro. Fora observado, ao longo da pesquisa, que a ideia inicial do movimento - evitar que profissionais da área da educação se beneficiem de sua posição para promover suas concepções ideológicas, morais e partidárias - tem fundamento e que norteiam a construção de programas para o ensino brasileiro, porém, deve haver cuidado para que o real interesse do grupo não seja utilizado como camuflagem do interesse de alguns em promover de suas ideias e para a criação de um instrumento legal que impeça manifestações por parte dos alunos, incentivando a formação de uma população passiva, possibilitando assim, a magnitude do governo sobre sua população.
\end{abstract}

Palavras-Chave: Ensino brasileiro; professores; doutrinação; ideologias.

\section{Resumen}

El presente artículo estudia la oposición al movimiento ya la implantación del programa "Escuela sin Partido" en la enseñanza brasileña con datos recolectados a partir de investigación bibliográfica y analizados por el método de comparación. El trabajo se dividió en tres bloques: en el primero, se presentan los defensores del programa, exponiendo los principales puntos del histórico y de los objetivos del grupo "EscuelasemPartido.org", de los contextos del Proyecto de Ley $n^{\circ}$ 190/2015-RS y del Proyecto de Ley del Senado Federal $n^{\circ}$ 193/2016, ponderando sobre los resultados de los años de 2016 y 2017 de la encuesta del Senado Federal referente al asunto. Las ideas contrarias al movimiento ya los proyectos de ley se apuntan en el segundo bloque. En el último bloque, utilizando referencias que versan sobre el tema, se hace reflexiones críticas para ayudar al lector a definir su posición sobre la implantación del programa al actual modelo de enseñanza brasileño. En la investigación, que la idea inicial del movimiento - evitar que profesionales del área de la educación se beneficien de su posición para promover sus concepciones ideológicas, morales y partidarias - tiene fundamento y que orientan la construcción de programas para la enseñanza brasileña sin embargo, debe haber cuidado para que el real interés del grupo no sea utilizado como camuflaje del interés de algunos en promover de sus ideas y para la creación de un instrumento legal que impida manifestaciones por parte de los alumnos, incentivando la formación de una población pasiva, permitiendo así la magnitud del gobierno sobre su población.

\footnotetext{
${ }^{1}$ Bacharel em Administração; Mestranda em Políticas Públicas da Universidade Federal do Pampa; São Borja, Rio Grande do Sul; paulafssf@gmail.com;

${ }^{2}$ Doutor em Ciencias Políticas y Sociología pelo Universidad Complutense de Madrid, Espanha; Professor Adjunto da Universidade Federal do Rio Grande do Sul e do Programa de Pós-Graduação em Políticas Públicas da Universidade Federal do Pampa; Porto Alegre, Rio Grande do Sul; alfredogugliano@ hotmail.com.
} 
Palabras claves: Enseñanza brasileña; profesores; adoctrinamiento; ideologías.

\begin{abstract}
The present article studies the opposition to the movement and the implantation of the program "School without Party" in the Brazilian education with data collected from bibliographical research and analyzed by the method of comparison. The work was divided in three blocks: in the first one, the program's proponents are presented, exposing the main points of the history and objectives of the group "EscolasemPartido.org", of the contexts of Bill No. 190/2015-RS and of the Project of Federal Senate Law no. 193/2016, pondering on the results of the 2016 and 2017 years of the Federal Senate poll on the subject. Ideas opposing the movement and bills are pointed out in the second block. In the last block, using references that deal with the subject, critical reflections are made in order to help the reader to define their position on the implementation of the program to the current model of Brazilian education. It was observed throughout the research that the initial idea of the movement - to prevent professionals from the education area from benefiting from their position to promote their ideological, moral and partisan conceptions - is based and that guide the construction of programs for Brazilian education , however, care should be taken that the real interest of the group is not used as a camouflage of the interest of some in promoting their ideas and in the creation of a legal instrument that prevents students from demonstrating, encouraging the formation of a passive population, thus making possible the magnitude of the government over its population.
\end{abstract}

Keywords: Brazilian teaching; teachers; indoctrination; ideologies.

\title{
1. Introdução
}

Ao estudar e compreender a história do estabelecimento da Constituição Federal de 1988 - elaborada em um período pós-ditatorial e como resposta às demandas da sociedade requeridas, em sua maioria, nas instâncias de participação social - entende-se que as políticas públicas no nosso país, são dependentes de uma série de atividades e coalizões para que sejam consolidadas. A promulgação da Carta Magna brindou à população do país com a proteção da possibilidade da participação como apreciadores das ações governamentais, seja por meio dos conselhos ou por manifestações coletivas ou individuais. Partindo desta concepção, este artigo procura responder se as consequências da possível implantação do programa "Escola sem Partido" ao ensino brasileiro podem implicar em repressão ou liberdade tanto para alunos quanto para professores.

Para melhor elucidar as coalizões existentes em torno da implantação do programa ao ensino brasileiro, o artigo está dividido em três blocos: no primeiro, são apresentados os defensores do programa Escola sem Partido, através da exposição dos principais pontos do histórico e dos objetivos do grupo do movimento "EscolasemPartido.org", dos contextos do Projeto de Lei do Senado Federal no 193/2016 e do Projeto de Lei da Assembleia Legislativa do estado do Rio Grande do Sul no 190/2015, bem como, e as justificativas utilizadas pelos seus proponentes e os resultados da enquete do Senado Federal referente à ideia do primeiro projeto nos anos de 2016 e 2017; as ideias contrárias ao movimento e aos projetos de lei, são apontadas no segundo bloco. No último, utilizando de referências bibliográficas que versam 
sobre o assunto, foram feitas reflexões críticas de modo a auxiliar o leitor a definir sua posição sobre a implantação do programa ao atual modelo de ensino brasileiro.

\section{Metodologia}

Este artigo apresenta a compilação de informações adquiridas a partir de pesquisa bibliográfica realizada na internet para obtenção de artigos que versem sobre o programa Escola sem Partido, uma vez que o tema é recente e até a conclusão do trabalho não haviam periódicos voltados precisamente ao assunto, somente as temáticas são discutidas por quem se opõe ou o defende. A pesquisa bibliográfica auxilia o investigador a possuir a cobertura de uma gama de fenômenos muito mais ampla do que se fosse pesquisar diretamente, sendo importante quando o problema de pesquisa requerer dados muito dispersos pelo espaço (GIL, 2008, p.50).

Para que compreender o processo que envolve o assunto, utilizou-se do método comparativo que permite a descoberta de regularidades, deslocamentos e transformações, identificando semelhanças e diferenças, explicitando as determinações mais gerais que regem os fenômenos sociais. Este método pode ser aplicado em qualquer pesquisa no campo das ciências sociais, para a análise de um evento singular ou para o estudo de uma série de casos previamente escolhidos (SCHNEIDER e SCHIMITT, 1998, p. 1).

\section{Escola Sem Partido: Movimentos e Projetos de Lei Favoráveis}

O tema "Escola sem Partido" foi um dos assuntos mais discutidos no País a partir do ano de 2015, somente ofuscado na mídia e redes sociais no decorrer dos eventos envolvendo o processo de impeachment da presidente Dilma Rousseff em agosto de 2016 e das denúncias de corrupção envolvendo a empresa Odebrecht e as ações da Operação Lava Jato. A corrente de pensamento que levou à ideia de implantação do programa teve início com a criação do movimento "EscolasemPartigo.org" e o ápice da discussão, especialmente nas redes sociais, instaurou-se a partir do protocolo do projeto de lei n 193 de 2016 no Senado Federal para a inclusão do programa às diretrizes e bases da educação nacional (SENADO FEDERAL, 2016b).

\subsection{Movimento "Escolasempartido.org"}

O "EscolaSemPartido.org" foi fundado em meados de 2004 e com princípios norteados pela preocupação de alguns em pais em coibir a possível doutrinação dentro das salas de aula. O ponto de convergência de ideias acontece no endereço eletrônico do movimento, idealizado para que os seus apoiadores divulguem depoimentos e o ponto de vista 
pessoal sobre situações em que os profissionais da área da educação buscaram forçar as opiniões dos discentes. Seus defensores relatam situações em que alunos teriam sido coagidos às opiniões de professores. (ESCOLASEMPARTIDO.ORG, 2016).

Os objetivos do movimento baseiam-se, praticamente, na ideia da "descontaminação e desmonopolização política e ideológica das escolas", sustentando que essas instituições devem adotar medidas para assegurar a diversidade de perspectivas ideológicas, para que haja o respeito à integridade intelectual e moral dos estudantes e os pais tenham o direito de educar seus filhos de acordo com suas próprias convicções de moral. Esses propósitos são sustentados pelo apoio às iniciativas que se igualem às finalidades do movimento, através de orientação aos estudantes e pais para o enfrentamento às situações debatidas, analisando e expondo opiniões sobre bibliografias, livros didáticos e conteúdos programáticos que reflitam sobre o tema, visando ampliar o conhecimento da população sobre o tema "doutrinação ideológica", mediante a divulgação de atos normativos, códigos de ética, pareceres, estudos científicos, artigos escritos ou digitais dedicados ao assunto (ESCOLASEMPARTIDO.ORG, 2016).

O idealizador do movimento EscolaSemPartido.org é Miguel Nagib ${ }^{3}$, advogado e membro da Procuradoria Geral do Estado de São Paulo no escritório de Brasília. Em pesquisa à internet, é possível encontrar alguns sites ${ }^{4}$ que se referem a ele, também, como ex-assessor do Supremo Tribunal Federal. No dia 21 de julho de 2016, quando esta pesquisa estava sendo elaborada, foi disponibilizada pela página eletrônica UOL - Educação, uma reportagem da jornalista Janaina Garcia em que Nagib opina sobre as discussões envolvendo o programa e o grupo.

Nesta editorial, Nagib diz acreditar que os opositores ao programa não são somente pensadores de esquerda, mas que também as pessoas de direita fazem parte desse grupo e, segundo ele, estão temerosos por possuírem vinculação religiosa e, em alguns momentos, se aproveitam das aulas para realizar algum tipo de proselitismo. O temor desse grupo de pessoas, segundo ele, é um equívoco, pois serão asseguradas as promoções de suas ideias e crenças em sala de aula. Na sua concepção, o intento dos projetos de lei apresentados sobre o

\footnotetext{
${ }^{3}$ Não é possível relatar a trajetória do profissional, pois em julho de 2017, somente constava a sua inscrição junto às Ordens dos Advogados do Brasil (OAB) e ele não possuía currículo cadastrado na Plataforma Lattes do Conselho Nacional Desenvolvimento Científico e Tecnológico (CNPQ)

${ }^{4}$ Ver: Portal da Ordem dos Advogados do Brasil - ES. Disponível em: http://www.oabes.org.br/noticias/oab-escondena-censura-em-sessao-que-debateu-escola-sem-partido-na-ales-558308.html. Publicado em 27 Junho 2017; Portal Esquerda Caviar. Disponível em: http://caviaresquerda.blogspot.com.br/2016/06/quem-e-miguel-nagiblider-do-movimento.html. Publicado em 07 Junho 2016.
} 
assunto, é voltado somente para a afixação de um cartaz afirmando os deveres dos profissionais da educação. Alega ainda que "o professor não poder promover seus próprios interesses ou concepções ideológicas não o impede de apresentar seus pontos de vista" desde que não incite os alunos a manifestações ou ideologias partidárias.

O advogado comenta que alguns opositores fazem alusão do projeto de lei à mordaça ${ }^{5}$, o que ele considera uma opinião equivocada, pois defende que não está sendo pregada a censura ou coerção à liberdade de expressão e sim a liberdade do aluno aceitar ou não o que o professor apresenta em sala de aula sem que esse possa vir a sofrer sansões por defender a sua opinião (GARCIA, 2016b). Para Nagib, os contrários à implantação do programa ao ensino brasileiro, em sua maioria, são professores com opiniões e preferências ideológicas ou políticas, portanto a maior oposição ainda vem desses profissionais que estão organizados, "que não querem e não aceitam os limites colocados pelo programa" afirmando não haver outra posição lógica para essa visão (GARCIA, 2016b) e complementa que:

\begin{abstract}
Nossa proposta de lei não se opõe a que temas políticos sejam debatidos - o que não pode é isso ser imposto pelo professor. Ele pode revelar suas crenças sem impô-la aos alunos, não é isso que se pretende banir da sala de aula. Apenas uma zona é que não pode ser invadida pelo Estado e pelo professor, e que compete à família, é reservada à ação da família: as questões de natureza religiosa e moral. Fora isso, não se propõe interdição de nenhuma área ao debate. (GARCIA, 2016b).
\end{abstract}

Quando questionado se "discutir questões relativas à situação política do País, por exemplo, na universidade, não faz parte da formação de cidadãos”, Nagib (GARCIA, 2016b) diz entender que, se o debate é travado em termos acadêmicos, ele não considera uma violação da liberdade de crença do aluno.

Sobre as possíveis denúncias que incentivaram a criação do movimento, Nagib afirma que existem vídeos, depoimentos em redes sociais, livros didáticos e reportagens que formam um conjunto de evidências sobre os abusos de doutrinação ideológica que ocorrem nas salas de aulas. Por fim, Nagib diz abster-se de apoiar qualquer opinião sobre os Projetos de Lei para implantação do programa no ensino dos estados e do país, pois considera que o importante é a defesa dos ideais do movimento, independente de se tornar regulamento ou não (GARCIA, 2016b).

\footnotetext{
${ }^{5}$ Ver: Portal A Notícia. Disponível em: http://anoticia.clicrbs.com.br/sc/politica/noticia/2016/06/sob-protestosprograma-escola-sem-partido-e-discutido-em-joinville-5886502.html. Publicado em: 07 Junho 2016. Acesso em 22/07/2016
} 


\subsection{Projeto de Lei do Senado Federal no 193/2016}

Em maio de 2016, foi proposto pelo senador Magno Malta (Partido Republicano - ES), o projeto de lei n ${ }^{\circ} 193$, que visa a inclusão do "Programa Escola sem Partido" entre as diretrizes e bases da educação nacional. O projeto, até a conclusão deste trabalho, estava em tramitação no Senado Federal e as últimas movimentações datam de junho de 2016, sem previsão para entrar em pauta de votação (SENADO FEDERAL, 2016b).

$\mathrm{Na}$ justificativa, o autor do projeto afirma que foi inspirado na luta do movimento "EscolasemPartido.org" e acusa os professores de se aproveitar da autoridade que possuem em sala de aula para induzir o aluno às "determinadas correntes políticas e ideológicas", podendo contrariar os padrões de julgamento e de conduta moral, que são ensinados pelos pais ou responsáveis, especialmente os que tratam da moral sexual (SENADO FEDERAL, 2016c, p. 05). Afirma também que, com a inclusão do programa, a educação do país deverá atender aos princípios como a neutralidade política, ideológica e religiosa do Estado, o pluralismo de ideias no ambiente acadêmico, bem como a liberdade de aprender e ensinar, pois pensa que na vulnerabilidade do educando perante o professor e declarando que:

Parágrafo único. O Poder Público não se imiscuirá na opção sexual dos alunos nem permitirá qualquer prática capaz de comprometer, precipitar ou direcionar o natural amadurecimento e desenvolvimento de sua personalidade, em harmonia com a respectiva identidade biológica de sexo, sendo vedada, especialmente, a aplicação dos postulados da teoria ou ideologia de gênero. (SENADO FEDERAL, 2016c, pp. 01-02)

O método defendido pelo projeto, como forma de advertir os professores quanto ao assunto, é a afixação de cartazes nas salas de aulas e dos professores nas escolas com os deveres desses professores destacando a imparcialidade que devem ter em ensinar sobre questões políticas, sócio-culturais e econômicas, para que não prejudiquem os alunos que não possuam as mesmas características religiosas, políticas e ideológicas semelhante aos demais. Para as escolas confessionais e particulares, as quais possuem o ensino voltado para concepções, princípios e valores morais, religiosos ou ideológicos, a lei somente deverá exigir que os pais e responsáveis pelos alunos assinem de um "termo de autorização expressa para a veiculação de conteúdos identificados com os referidos princípios, valores e concepções", mediante a entrega de material informativo "que possibilite o pleno conhecimento dos temas ministrados e dos enfoques adotados" (SENADO FEDERAL, 2016c, p. 02). 
Ao longo do texto do projeto, observa-se que o foco principal é o professor, especialmente, no quinto parágrafo onde são enumerados alguns deveres a serem observados, tais como: não se aproveitar da audiência cativa dos alunos, não favorecer nem prejudicar alunos em razão dos seus próprios interesses, opiniões, concepções ou preferências ideológicas, religiosas, morais, políticas e partidárias ou da falta delas. O texto do projeto prevê que o ambiente escolar não deverá ser utilizado para propaganda político-partidária e os alunos não devem ser incentivados a participar de manifestações atos públicos e passeatas e, quando necessário tratar de questões políticas, socioculturais e econômicas, devem ser apresentadas de forma justa, demonstrando as principais versões, teorias, opiniões e perspectivas concorrentes a respeito (Senado Federal, 2016c. pp. 02-03).

No projeto é estudada a obrigatoriedade da criação de um canal de comunicação onde serão recebidas as reclamações referentes ao assunto debatido. Essas denúncias deverão ser encaminhadas para o Ministério Público o qual ficará incumbido de apurar e tomar as providências cabíveis quanto à aplicação legal de sansões aos profissionais que infringirem o regulamento, quando for o caso. Por fim, o projeto de lei prevê a aplicação, quando cabível, às políticas e planos educacionais, aos materiais didáticos e paradidáticos, bem como às avaliações para o ingresso no ensino superior, provas de concurso para o ingresso na carreira docente, e às instituições de ensino superior. Tal medida fará com alguns materiais didáticos não sejam permitidos para a distribuição gratuita nas instituições nem para debate em sala de aula (SENADO FEDERAL, 2016c, pp. 03-04).

$\mathrm{Na}$ justificativa para a criação do projeto, o senador destaca que o termo "liberdade de ensinar" é assegurado pela Constituição Federal, mas não deve ser confundida com a "liberdade de expressão", pois, segundo ele, não existe no exercício da docência, sob pena de anular a liberdade de consciência e de crença dos estudantes. Além disso, faz uma associação da prática da doutrinação política e ideológica nas escolas à "violação ao próprio regime democrático, na medida em que ela instrumentaliza o sistema público de ensino com o objetivo de desequilibrar o jogo político em favor de determinados competidores" (SENADO FEDERAL, 2016c, pp. 05-06).

Utilizando do princípio constitucional da impessoalidade, o senador diz que, como a escola pública pertence ao Estado, não deve haver qualquer tipo de benefício ou perseguição a ninguém por causa de sua escolha política e ideológica, que deve haver neutralidade política e ideológica, do mesmo modo, acredita que o ensino de religiões nas escolas direciona para um pensamento moral que podem ofender outras crenças religiosas. E conclui que o principal objetivo desse projeto de Lei é informar aos alunos que os docentes não poderão exercer a sua 
liberdade de ensino para doutriná-los a um determinado pensamento ideológico, assimilando a regra ao direito do aluno de ser informado sobre os próprios direitos, que "é uma questão de estrita cidadania" (SENADO FEDERAL, 2016c, pp. 06-07).

\subsubsection{Enquete do Senado Federal}

Para identificar a opinião da população quanto ao projeto de Lei, o Senado Federal criou uma Consulta Pública ${ }^{6}$ na página eletrônica do órgão. Para fins de demonstração nesse artigo, foram visualizadas as contagens de votos computados até o dia 21 de julho de 2016 (figura 1) e até o dia 30 de julho do ano seguinte (figura 2).

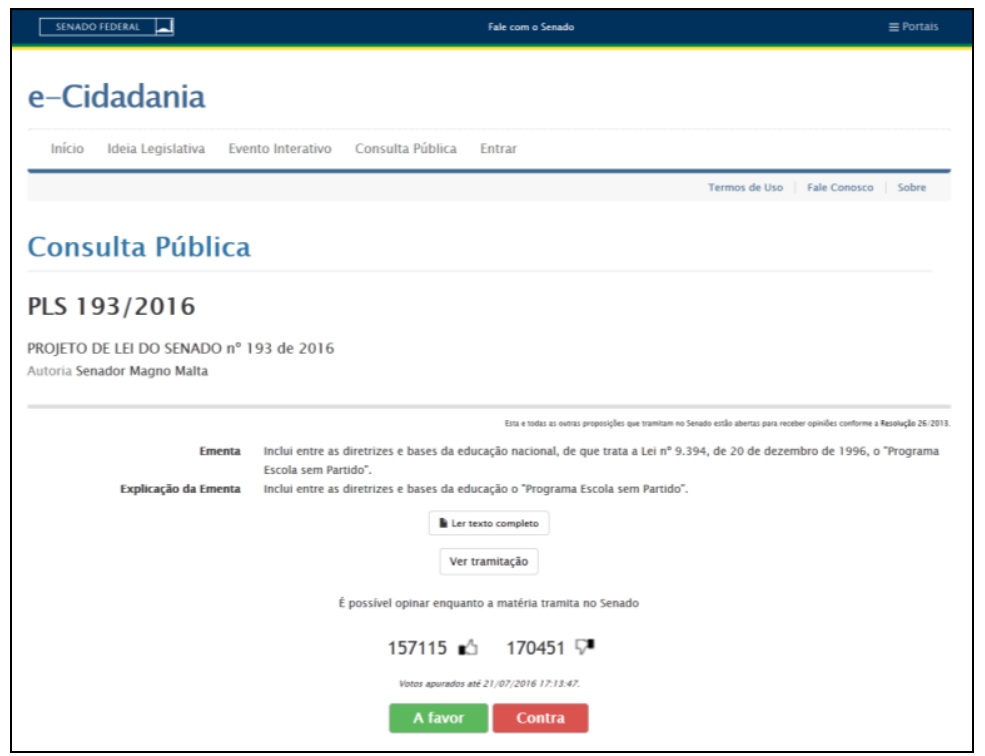

Figura 1: Resultado parcial da enquete do Senado Federal para o Projeto de Lei n ${ }^{\circ}$ 193/2016 em 21 de Julho de 2016 Fonte: Consulta Pública - PLS 193/2016 : Portal e-Cidadania - Senado Federal, em 21/07/2016.

Na figura 1, capturada em 2016, os defensores do projeto de Lei somavam 47,96\% (quarenta e sete vírgula noventa e seis por cento) dos votantes, ilustrando a insatisfação e certa divisão de opinião em relação ao assunto. Após um ano de tramitação do projeto e em um período posterior aos acontecimentos que ensombraram a discussão sobre o assunto nas redes sociais e mídia, os que não concordam com o conteúdo do Projeto de Lei proposto pelo senador Magno Malta ainda são maioria, sendo a taxa reprovação de 51,31\% (cinquenta e um

\footnotetext{
${ }^{6}$ Para votar, o cidadão só precisa acessar o site do Senado Federal, escolher o projeto de seu interesse e clicar em sua opinião. No primeiro acesso, é necessário realizar um cadastro com os dados como nome completo, e-mail, a unidade federativa em que reside e criar uma senha e, ainda, acessar com os perfis das redes sociais Facebook ou g+ (do Gmail). Para quem já votou em outros projetos, somente é necessário acessar com o e-mail e senha.
} 
vírgula trinta e um por cento). Tal situação expõe que a divisão de opiniões ainda persiste, mas houve uma pequena redução na quantidade votantes contrários ao projeto.

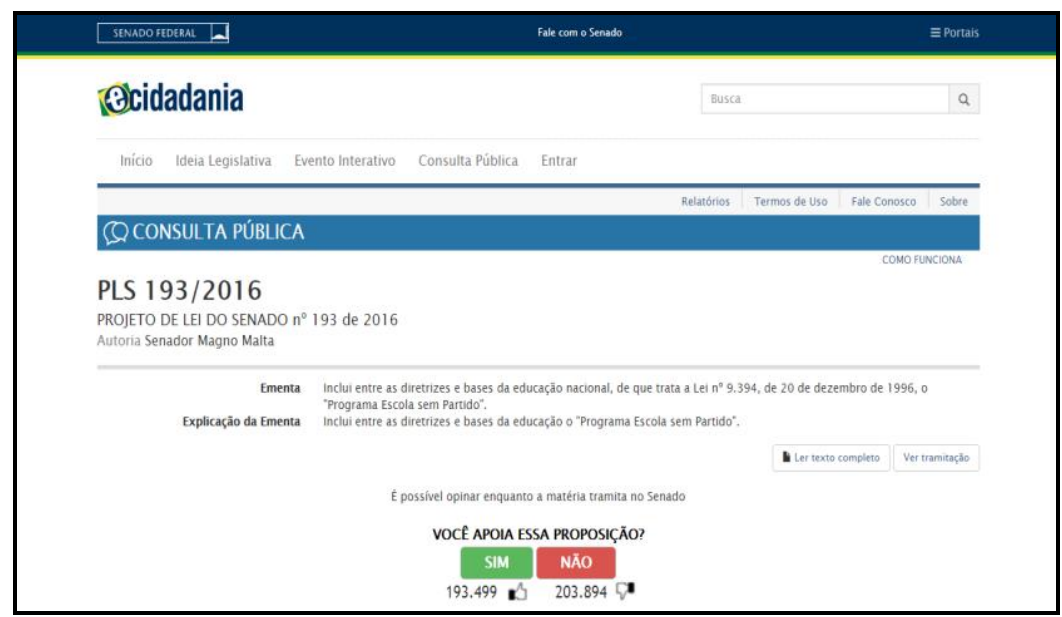

Figura 2: Resultado parcial da enquete do Senado Federal para o Projeto de Lei no 193/2016 em 30 de julho de 2017 Fonte: Consulta Pública - PLS 193/2016 :: Portal e-Cidadania - Senado Federal, em 30/07/2017.

\subsection{Projeto de Lei $n^{0}$ 190/2015-RS}

Até o mês de julho de 2016, ao menos dezenove estados do País tinham projetos de lei para a implantação do programa "Escola sem Partido", conforme apresentado no mapa (figura 3), onde é possível identificar os estados que já possuem a lei em vigor, onde ainda estão sendo discutidas em suas assembleias legislativas e alguns casos onde sequer existem projetos de lei em seus municípios, como nos estados do Acre, Mato Grosso e Amapá (SANTANA, 2016).

No Rio Grande do Sul, o projeto de lei para implantação do programa "Escola sem Partido" foi protocolado na Assembleia Legislativa (AL-RS) em maio de 2015 pelo deputado estadual Marcel van Hattem do Partido Progressista - PP (AL-RS, 2016), utilizando de texto semelhante ao projeto federal, com uma adaptação da justificativa à opinião do parlamentar. Após passar pela Comissão de Constituição e Justiça da casa legislativa (CCJ-AL-RS), foi solicitado o arquivamento do projeto ao Departamento de Assessoramento Legislativo (DALAL-RS) o que aconteceu em outubro de 2016, mesmo após proponente entrar com recurso contra a decisão. 


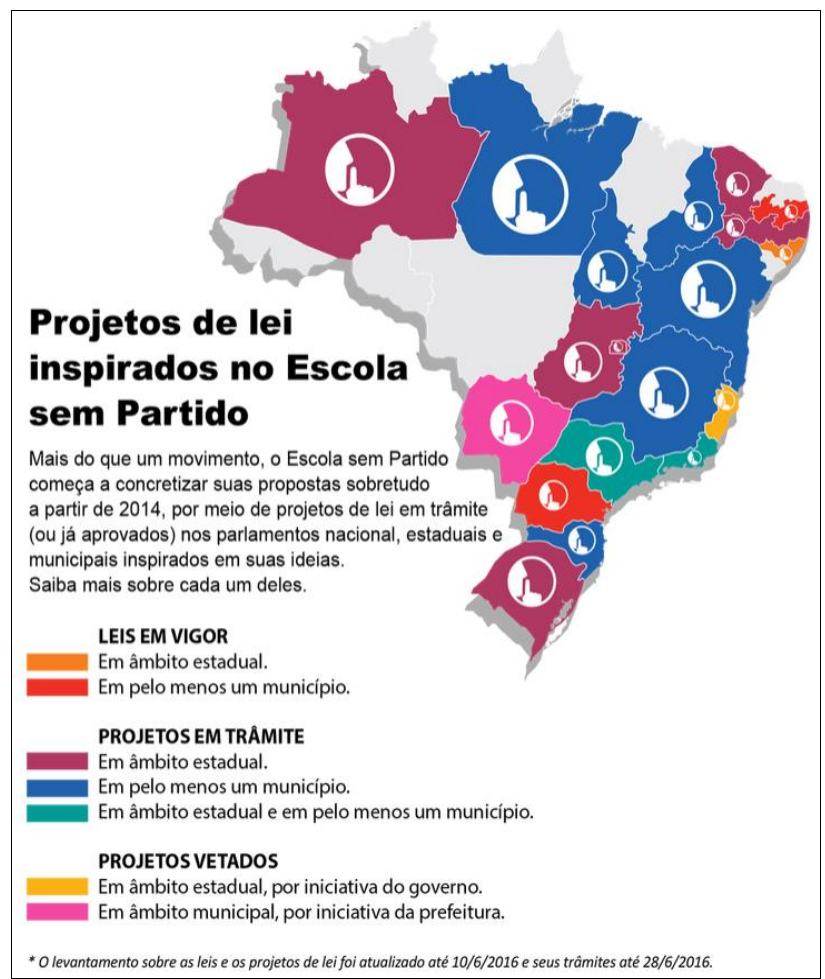

Figura 3: Projetos de lei para implantação do programa "Escola sem Partido" nos estados brasileiros Fonte: Portal da EBC - Ana Elisa Santana (2016).

Na justificativa, o político sugere a implantação do programa "Escola sem partido" ao sistema estadual de ensino desde a realização de concursos para contratação de professores, acreditando que a própria autoridade pública deve "abster-se de exigir dos candidatos determinada posição partidária, ou da adoção de determinada visão ideológica”. Hattem reforça a ideia de que o Estado deve ser imparcial ao realizar concurso público, evitando refletir a "ideologia do governo do momento ou de quem quer que seja", para que a educação do estado não sirva aos "interesses transitórios de uma determinada ideologia" (AL-RS, 2016).

\section{Oposição ao Programa "Escola Sem Partido"}

Como comentado anteriormente, os que se opõem à implantação do programa Escola sem Partido ao ensino brasileiro o associam à "Lei da Mordaça", uma comparação das regras dos projetos de lei às censuras sofridas durante a ditadura militar. Isso porque acreditam que este projeto é uma máscara para influenciar na consciência do educando, objetivando formar cidadãos incapazes de utilizar da capacidade de intervir junto ao governo, tal como vemos na opinião de um dos opositores ao projeto, o ex-ministro Renato Ribeiro.. 


\section{1. "Escola Sem Partido" Sob a Visão do Ex-Ministro da Educação Renato Janine}

\section{Ribeiro}

Em paralelo à entrevista com Miguel Nagib, foi disponibilizada uma reportagem, elaborada pela mesma jornalista, feita ao professor Renato Janine Ribeiro - com um dos opositores do programa - titular da disciplina Ética e Filosofia Política da Universidade de São Paulo - USP desde 1984, desde que concluiu o seu doutorado (CNPQ, 2017). Também foi Ministro da Educação do Brasil em 2015 durante o governo Dilma.

Ele é contrário à concepção do grupo e à implantação do programa "Escola sem Partido" no ensino brasileiro, pois acredita que se trata de uma corrente de pensamento composta por pessoal ligado a "uma direita mais extrema" e a principal crítica do professor ao programa é por entender que existem questões prioritárias a serem discutidas referentes a educação no país e não estão acontecendo por conta da atenção que estão dando ao tema em epígrafe. Para ele, o assunto está sendo utilizado como uma "cortina de fumaça de caráter puramente ideológico, e não educacional, nem educativo" encobrindo "os reais e mais urgentes" problemas da educação brasileira, principalmente os relacionados aos baixos índices de alfabetização e em pensar a escola como construtora de futuros cidadãos (GARCIA, 2016a).

Em relação às ações em sala de aula, consideradas pelos defensores do movimento contra os valores e crenças adquiridos em família, o ex-ministro é enfático ao afirmar que as "ciências sempre incluem controvérsias [...], se não ensinamos isso, ensinamos errado" independente da disciplina que está sendo ministrada e destaca que "o conhecimento que precisa ser passado é essencialmente científico - nas quais não se inclui o criacionismo, que é uma teoria religiosa" (GARCIA, 2016) e assevera:

Com todo respeito, mas família é família, e sociedade é sociedade: a família pode ter crenças de preconceito homofóbico ou contra a mulher, por exemplo, e não se pode deixar que um jovem nunca seja exposto a um ponto de vista diferente desses. Ele tem que ser exposto a outros valores. (GARCIA, 2016).

Renato Ribeiro alega que muitas são as religiões que "tem uma visão um tanto preconceituosa em relação à mulher e ao homossexual", mas a escola não tem o objetivo de modificar o pensamento de fé da pessoa e outros valores, é uma forma de socialização, como "uma maneira de ela sair da sua família e ser exposta a um mundo muito mais amplo". Em relação à concepção "meus filhos, minhas regras" quando se trata de religião e valores morais, o professor salienta que bons pais são aqueles que educam o filho para ele não precisar mais 
deles, para que ele tenha autonomia e possa enfrentar o mundo graças à formação que ele teve, sem que tenha que "se tornar um clone dos pais" (GARCIA, 2016a).

Em sua opinião, deve ser respeitada a diferença de sentimentos e opiniões, pois entende que, ao educar o indivíduo "não se trata de acabar com o papel dos pais na educação, mas de fazer notar que, ainda que os pais tenham um papel insubstituível na vida dos filhos, eles têm que criá-los para serem livres e fazer suas escolhas". Para ele, tanto os pais quantos os professores devem ser formadores dos jovens para a liberdade (GARCIA, 2016a).

Renato Ribeiro (GARCIA, 2016a) não descarta a existência de doutrinação ideológica nas escolas, mas não acredita que seja prioritário de um ou de outro partido político e que não só os princípios de esquerda são defendidos. Acredita que as publicações comentadas pelos defensores dos movimentos são casos isolados, não podendo ser consideradas como uma estratégia de disseminação de ideologias e entende que é grave a tentativa de impedir os professores de ensinar o que é contrário aos valores da família e "se esta tem valores que passam pela desigualdade entre as pessoas, não, a escola não pode se calar”.

Quanto à providência a ser tomada pelos pais que identificarem a tentativa de doutrinação de seu filho por um professor, Renato Ribeiro sugere que estes devem procurar ajuda na escola, cientes de que isso não significa que estejam corretos e que a verdade que eles acreditam pode não ser a considerada e ensinada pelas escolas e livros. Destaca, também, que o movimento "Escola sem Partido" defende uma ideia de retrocesso de pensamento que vem a ferir todas as conquistas de liberdade que foram obtidas até hoje (GARCIA, 2016a).

\footnotetext{
É inevitável que quem sempre foi privilegiado e de repente vê o seu privilegio ser posto em cheque não vai gostar - isso surgiu de novo, com força, nas mensagens "Quero o meu País de volta" nas recentes manifestações pelo impeachment. "Quero o País em que eu tenho vantagem sobre os outros" de volta; essa é a mensagem - e é muito difícil trabalhar isso. (GARCIA, 2016a).
}

Renato Ribeiro se diz incomodado com a expectativa de aprovação dos projetos de lei embasados no programa, pois não acredita que essa é uma "questão educadora nem educativa, mas ideológica, e defendida por pessoas que abraçam uma determinada ideologia a qual não querem que seja contestada" e reforça que a discussão deveria ser voltada para assuntos que beneficiariam os alunos tal como a formulação de uma base curricular apropriada para a realidade do nosso país. O ex-ministro destaca a importância dos pais apoiarem as escolas incentivando seus filhos na disseminação do conhecimento e não apoiar uma questão que irá desviar o foco das verdadeiras necessidades da educação brasileira, uma "cortina de fumaça 
que tenho a impressão que movimentos como o Escola sem Partido têm criado" (GARCIA, 2016a)

\section{Reflexões Críticas}

Ao longo dos textos aqui apresentados, notou-se o envolvimento de temáticas como: participação, papel do educador e dos pais para a formação de futuros cidadãos, política, dentre outros. Para que o leitor desenvolva uma opinião sensata sobre o assunto, apresento referências bibliográficas que versam sobre as temáticas apresentadas:

\subsection{O Papel do Professor e dos Pais como Educadores}

O Projeto de Lei do Senado Federal está intimamente ligado à liberdade e autoridade dos professores em sala de aula e quanto à indução de opiniões referente aos valores morais e éticos que podem vir a ferir ideologias familiares e religiosas. A Constituição Federal (1988) defende a inviolabilidade da liberdade de consciência e de crença, assegurando o livre exercício dos cultos religiosos, inclusive prevendo a criação de lei para garantir a proteção de locais de culto e a suas liturgias, para que ninguém seja privado de direitos por motivo de crença religiosa ou de convicção filosófica ou política, com algumas exceções. Também defende a livre manifestação do pensamento, vedando o anonimato.

A Lei de Diretrizes e Bases da Educação Nacional (1996) defende a "liberdade de aprender, ensinar, pesquisar e divulgar a cultura, o pensamento, a arte e o saber", bem como o pluralismo de idéias e de concepções pedagógicas devendo haver respeito à liberdade e apreço à tolerância. Ribeiro (2010, p. 164) acredita que é através de uma educação com caráter ideológico que são estimulados os valores politicamente significativos. Assim como, pertencer a uma classe social definida, pode não interferir em nossa maneira de pensar, por existir vários fatores que podem influenciar na consciência da nossa própria situação e incentivar à visão dos interesses da classe oposta.

Ramos (2011, pp. 49-50) afirma que, depois da família, a escola é uma "instituição cuidadora", na qual o bom professor é aquele que "ressignifica as imagens pessoais de forma positiva" a fim de unir o saber de si mesmo e dos demais. No ensino é possível acolher os posicionamentos que se articulam em sala de aula, preservando a capacidade de criar e assim, encorajar os estudantes a falarem os incentivando à novas aprendizagens. Da Luz (2011, p. 198) destaca que o ambiente educacional deve oportunizar ao educando "a ressignificação, o recriar a sua história pessoal, para dar sentido e sentir-se autor de sua história", ou seja, através do acolhimento em uma instituição de ensino, o aluno deverá ser incentivado a construir a sua opinião. 
Por conseguinte, Ramos (2011, pp. 43-45) descreve que é necessário o ser humano se desprender das suas concepções do "seu Eu", aceitando a figura do outro, afim de “desenvolver vínculos não fixados em imagens narcísicas”, que naquele momento é “importante aceitar a dependência, o pertencimento, o reconhecimento das diferenças e semelhanças nas circunstâncias educativas formais e informais" para que assim crie a sua própria independência. $\mathrm{O}$ educador tem a responsabilidade também de saber que existem várias formas de vida em uma sala de aula e para saber conduzir o ensino de acordo com a necessidade e características dos seus educandos. A autora afirma ainda que, para ensinar e aprender, é necessário “tolerar frustrações, calar necessidades, suportar a troca e a presença do outro".

\begin{abstract}
Os estudantes precisam cruzar diferentes zonas de diversidade cultural, de maneira que refaçam a relação cognitiva e afetiva com a sociedade e com o outro. Professor e alunos devem aprofundar a visão social, a ética e a pluralidade; a diversidade e a tão estranha diferença, que rompem com o fixo unitário e narcísico, pois assim poderão tornar-se mais conscientes da complexidade e mais sensíveis às experiências humanas (RAMOS, 2011, p. 53).
\end{abstract}

Para a autora, o conhecimento surge da convivência, da trocas de saberes e conclui que é necessário que haja confiança no profissional e na escola, pois o professor "pode transformar o sujeito biológico em Ser de cultura", fazendo com que compreenda que no mundo a sua volta existem pessoas com pensamentos diferentes, mas que o semelhante deve ser reconhecido e as diferenças devem ser aceitas (RAMOS, 2011, p. 45).

O magistério público é a carreira que conta com o maior número de profissionais em todo o país. (...) Estes profissionais, todos os dias, mantêm contato direto com milhões e milhões de crianças e adolescentes na educação infantil e nos ensinos fundamental e médio, sem falar na educação profissional. A escola pública é o equipamento social mais difundido em todo território nacional. (COSTA, 2001, p. 18)

Rodriguez (2001, pp. 47, 51) denuncia que há uma fratura no sistema de educação básica no país, uma vez que todos os níveis de ensino deveriam ser devidamente planejados e articulados como um todo. $\mathrm{O}$ autor acusa que o governo federal tem se esquivado das suas responsabilidades enquanto há a necessidade da sua interferência no combate ao analfabetismo e aos baixos índices de qualidade no ensino fundamental.

A história da cidadania e a história de educação pública praticamente se confundem. Darcy Ribeiro costumava dizer que o Brasil é um país que sabe fabricar carros, submarinos, computadores, televisores, videocassetes, aviões e até mesmo satélites, mas que tem, historicamente, fracassado na sua tarefa de fabricar cidadãos, (...) a 
razão deste fracasso reside no fato de que "a fábrica de cidadãos", que é a escola pública, não estar funcionando como devia. (COSTA, 2001, p. 20).

Costa (2001, p. 19) discute sobre a necessidade de ressignificação da educação do nosso país, em que os brasileiros precisam mudar "profundamente o seu modo de ver, entender e agir diante da educação". Para que as escolas "comecem a mudar para melhor" é necessário encontrar a solução para os problemas que prejudiquem elementos como o salário, a carreira, as condições de trabalho, a formação inicial, a capacitação em serviço e o prestígio social do magistério. Importante também é o reconhecimento dessa categoria pelo Governo e pelo conjunto da sociedade "fora da retórica das campanhas políticas"

É importante entender, segundo Costa (2001, p. 24), que o professor é mais do que um simples cidadão, ele produz cidadãos. E esse profissional deve perceber que "está chamado a viver a cidadania dentro e fora da sala de aula", sendo imprescindível ter "uma consciência límpida e madura do papel que devemos ter diante dos educandos, de suas famílias e de toda a comunidade onde a escola está inscrita”.

\subsection{Crítica e Participação Social}

Sempre que um assunto é de interesse da população, a participação social e análise crítica, oposicionista ou favorável, devem ser consideradas para a tomada de decisão quanto ao apoio ou a negativa de defesa. Dallari (1999, p. 78-80) considera que criticar é uma importante forma de participação política, uma oportunidade que cada indivíduo tem de tomar suas próprias decisões e ajudar os demais a formarem suas opiniões. Entretanto, existem perigos a ser evitados antes de criticar, sendo grave a influência de preconceitos, tanto políticos, sociais, filosóficos, religiosos, raciais ao assunto e às pessoas que estão sendo analisadas. O outro ponto a ser observado é a confusão entre a aparência e a realidade, uma vez que:

A vida social de nosso tempo é muito dinâmica, a organização social é um emaranhado de situações e muitas vezes o mesmo indivíduo exerce vários papéis diferentes, sendo difícil distinguir quando ele age numa ou noutra qualidade. [...] Não é raro que os meios de divulgação serem manipulados para criar uma falsa imagem da realidade, ocultando os fatos ou uma parte deles ou apresentando-o de modo a orientar para certa direção a opinião de quem analisa e julga. (DALLARI, 1999, p. 78).

Sem falar, as situações em que governantes apresentam falsos motivos ou fornecem informações falsas ou distorcidas em seu favorecimento (Dallari, 1999, p. 78-79). Sobre as inverdades, Vaidergorn (2001, p. 79) assinala que elas passam a ter "foro de verdade" a partir de um círculo vicioso: após lançada a palavra, o ouvinte que, por admirar o orador, aceita e 
repassa a informação a outros, até que o falado retorne ao primeiro personagem, o que criou o pensamento, que o aproveita para confirmar e defender a sua ideia.

Tatagiba (2002, p. 100) relata que a "institucionalização da participação popular nas políticas públicas foi um grande avanço, uma conquista importante dos setores democráticos" e é preciso continuar e efetivar a prática dessa vitória da democracia. A nação deve utilizar da democracia para que o Estado não aja como soberano, se desfazendo de seu povo e implantando de políticas públicas, tal como é conveniente aos que dependem dos que estão no poder. Dallari (1999, pp. 27 e 32) narra que, desde milênios, na história da humanidade existe uma luta constante para que a população possa participar das decisões políticas. Atualmente, a disseminação das técnicas de comunicação favorece o desejo de uma participação mais ampla por parte da sociedade, porém, ainda há a tentativa por parte de um grupo elitizado em tomar as decisões que somente os favoreçam, embora as Constituições nos países procurem minimizar a ação desses.

A participação política é um dever moral de todos os indivíduos e uma necessidade fundamental da natureza humana. A participação intensa e constante de muitos é necessária para impedir que alguns imponham uma ordem injusta, que sempre acaba sendo prejudicial para todos". (DALLARI, 1999, p. 36).

Costa (2001, p.24) relata que o ex-ministro Hélio Beltrão dizia enxergar o Brasil como "um país de súditos" com cidadãos tímidos, inseguros, passivos e adeptos ao conformismo, tanto pessoas como organizações. O poder público, em vez de servir, julgava-se no direito de ser servido pelos cidadãos. Entretanto, é primordial, para a existência de políticas públicas de alcance a todos, que existam pensadores entre a população.

A população deve se mobilizar em grupo ou individualmente, não se acomodando diante dos mandos e desmandos dos que estão frente à máquina pública. Tal como Dallari (1999, pp. 37 e 39) destaca, "todos podem exercer alguma influência política, desde que tomem consciência de que são seres humanos iguais aos outros e de que não devem conformar-se com as injustiças" e participação política não é apenas participação eleitoral, e muitas vezes é mais eficiente por outros meios.

\section{Considerações Finais}

Neste artigo procurou-se absorver informações com o intuito de relatar e discutir o assunto e, principalmente, responder se a implantação do programa Escola sem Partido ao ensino brasileiro pode ser considerado um ato de repressão ou um ato de liberdade tanto para alunos quanto para professores. As reportagens advindas de endereços eletrônicos, em 
especial as duas entrevistas mediadas por Garcia (2016), foram adicionadas ao estudo como comprobatório do pensamento e do perfil dos que defendem e os que não corroboram com as concepções do grupo anterior.

Observou-se que a ideia inicial do movimento "EscolasemPartido.org" está voltada para à preocupação de pais e estudantes que sentiram-se lesados com a atitude de alguns professores, que segundo eles, se beneficiaram de sua posição para promover suas concepções ideológicas, morais e partidárias. Gozando do seu direito de liberdade de expressão, o grupo se uniu para que mais pessoas soubessem e tivessem coragem de não permitir a continuação desse fato.

Após as declarações feitas por Nagib em relação aos projetos de Lei apresentados aqui, surge a preocupação para que esses projetos estejam em sintonia com os objetivos do movimento e não sejam direcionados para uma disputa política, mesmo que não haja na possível lei uma alusão ao grupo. Nos projetos não existe uma identificação da diferença entre discussão acadêmica e partidária.

Assim sendo, é necessário que haja um cuidado para que o real interesse do grupo não seja utilizado como uma forma de camuflar o interesse de alguns para a promoção de suas ideias e, até mesmo, como uma forma legal de impedir manifestações por parte dos alunos e professores e, consequentemente, incentivar a formação de uma população passiva, possibilitando assim, a magnitude do governo sobre sua população. Os futuros cidadãos não podem ser privados da essência de questionar.

Ao analisar o projeto gaúcho, é notável a semelhança com projeto federal, porém a justificativa referenciando a transparência na realização dos certames para contratação de pessoal, afasta-se do foco do projeto federal e do grupo estudado que pregam a imparcialidade por parte dos professores no ensino em sala de aula. Também, não é revelado qual seria o perfil partidário e ideológico dos professores que não devem ser contratados após a implantação do programa e como a aplicação desse tipo avaliação deverá ser feita de maneira justa.

Acredito que a principal preocupação do parlamentar pode estar ligada aos contratos temporários de professores que é feito pelas Coordenadorias Regionais de Educação e não pelo setor de recursos humanos da Secretaria Estadual de Educação, porém, esse problema provavelmente não será resolvido com a implantação deste programa, o objetivo é outro. Penso que, ao barrar o profissional por conta de sua filiação política ou preferência ideológica, estará sendo lesado o princípio da liberdade de escolha e expressão, previsto na Constituição Federal (1988). 
Quanto aos impactos da aplicação do programa tanto a nível federal ou estadual, foi possível analisar a inexistência de estudos técnicos sobre o alcance e custo do programa Escola sem Partido ao governo, às instituições e profissionais da educação, aos alunos e pais, isso em termos jurídicos, financeiros e, até mesmo ideológicos. Encontram-se na internet, em especial, artigos contendo informações e opiniões advindas de diversas correntes ideológicas e partidárias sobre o assunto, a maioria não advém de cientistas ou analistas políticos.

Conclui-se que o movimento "EscolasemPartido.org" deve continuar como um amparo para os que se sentem lesados, porém a implantação do programa Escola sem Partido deve ser repensado e estruturado com mais semelhança aos objetivos do grupo, sem ferir a liberdade de escolha de ninguém. A ideia de coibir a intervenção e imposição por parte de alguns professores quando o assunto for relacionado à política, ideologias morais ou religiosas e liberdade de consciência deve continuar a ser defendida.

Porém, é de suma importância que a população permaneça atenta aos passos dos parlamentares para que não se aproveitem da sua condição para aplicar uma ditadura camuflada nas escolas. Todos devem observar para que os objetivos aprazíveis dos movimentos e projetos aqui apresentados não sejam distorcidos para concepções ideológicas agradáveis a instituições políticas e que possam ferir os direitos conquistados com a atual Constituição Federal.

\section{Referências}

COSTA, Antonio Gomes da. O professor como educador: um resgate necessário e urgente. Salvador: Fundação Luís Eduardo Magalhães, 2001. (Obra completa)

DALLARI, Dalmo de Abreu. O que é participação política. São Paulo: Brasiliense, 1999. (Obra completa)

DA LUZ, Renata Vanin. A árvore da sabedoria: uma história para professores. In: RAMOS, Maria Beatriz Jacques; FARIA, Elaine Turk (orgs.). Aprender e ensinar : diferentes olhares e práticas. Porto Alegre : PUCRS, 2011. p. 186-199. (Capítulo de Livro)

GIL, Antonio Carlos. Métodos e técnicas de pesquisa social. São Paulo : Atlas, 2008. (Obra completa)

Portal da Assembleia Legislativa do estado do Rio Grande do Sul (AL-RS). Disponível em: http://www.al.rs.gov.br/legislativo/ExibeProposicao/tabid/325/SiglaTipo/PL/NroProposicao/1 90/AnoProposicao/2015/Origem/Px/Default.aspx. Acesso em: 22 julho 2016.

Portal da Empresa Brasil de Comunicação. Reportagem "Escola sem Partido: entenda o que é movimento que divide opiniões na Educação" de Ana Elisa Santana. Disponível em: http://www.ebc.com.br/educacao/2016/07/o-que-e-o-escola-sem-partido. Publicado em 20 Julho 2016. Acesso em 20 Julho 2016. 
Portal da Presidência da República - Constituição Federal do Brasil (1988). Disponível em: http://www.planalto.gov.br/ccivil_03/constituicao/constituicaocompilado.htm. Acesso em: 31 julho 2017.

- Lei no 9.394 de 20 de dezembro de 2016. Disponível em:

http://www.planalto.gov.br/ccivil_03/leis/L9394.htm. Acesso em 31 Julho 2017.

Portal do Conselho Nacional Desenvolvimento Científico e Tecnológico - CNPQ. Disponível em: http://buscatextual.cnpq.br/buscatextual/visualizacv.do?id=K4783966Z8:. Acesso em: 31 Julho 2017.

Portal do movimento Escolasempartido.org. Disponível em http://www.escolasempartido.org. Acesso em: 21 Julho 2016.

Portal do Senado Federal. Disponível em: https://www12.senado.leg.br/ecidadania/visualizacaomateria?id=125666. Acessos em: 21 Julho 2016a e 30 Julho 2017.

Projeto de Lei do Senado $\mathrm{n}^{\circ}$ 193, de 2016. Disponível em: https://www25.senado.leg.br/web/atividade/materias/-/materia/125666. Acesso em 21 Julho $2016 b$.

Projeto de Lei do Senado no 193, de 2016. Disponível em:

https://legis.senado.leg.br/sdleg-getter/documento?dm=569947\&disposition=inline. Acesso em 21 Julho $2016 \mathrm{c}$.

Portal UOL Educação. Reportagem “"Escola sem Partido não é sério: é cortina de fumaça', diz ex-ministro" de Janaina Garcia. Disponível em:

http://educacao.uol.com.br/noticias/2016/07/21/escola-sem-partido-nao-e-serio-e-cortina-defumaca-diz-ex-ministro.htm\#fotoNav=4. Publicado em: 21 Julho 2016. Acesso em: 22 Julho $2016 b$.

Reportagem “'Pais devem processar doutrinadores', diz idealizador do Escola sem Partido" de Janaina Garcia. Disponível em:

http://educacao.uol.com.br/noticias/2016/07/21/pais-devem-processar-doutrinadores-dizidealizador-do-escola-sem-partido.htm. Publicado em: 21 Julho 2016. Acesso em: 22 Julho 2016a.

RAMOS, Maria Beatriz Jacques; FARIA, Elaine Turk. Autoestima: relação professor e aluno. In: RAMOS, Maria Beatriz Jacques; FARIA, Elaine Turk (orgs.). Aprender e ensinar : diferentes olhares e práticas. Porto Alegre : PUCRS, 2011. p. 42-56. (Capítulo de Livro)

RIBEIRO, João Ubaldo. Política: Quem manda, por que manda, como manda. Rio de Janeiro : Objetiva, 2010. (Obra completa)

RODRIGUEZ, Vicente. Financiamento da educação e políticas públicas: O Fundef e a política de descentralização. Cadernos Cedes, ano XXI, nº 55, novembro/2001. (Artigo em Periódico Físico) 
SCHNEIDER, Sergio; SCHIMITT, Cláudia Job. O uso do método comparativo nas Ciências Sociais. Cadernos de Sociologia, Porto Alegre, v. 9, p. 49-87, 1998. (Artigo em Periódico Físico)

TATAGIBA, Luciana. Os Conselhos Gestores e a Democratização das Políticas Públicas no Brasil. In: DAGNINO, Evelina (org.). Sociedade civil e espaços públicos no Brasil. São Paulo : Paz e Terra, 2002. p. 43-107. (Capítulo de Livro)

VAIDERGORN, José. Uma perspectiva da globalização da Universidade brasileira. Cadernos Cedes, ano XXI, nº 55, novembro/2001. p.78-91. (Artigo em Periódico Físico) 